\title{
Self-Propagating High-Temperature Synthesis of Materials Based on Tungsten Carbide for One-Pot Hydrolysis-Hydrogenolysis of Cellulose Into Ethylene Glycol and 1,2-Propylene Glycol
}

\author{
Nikolay V. Gromov ${ }^{\mathrm{a}, \mathrm{b}}$, Alekasandr A. Zhdanok ${ }^{\mathrm{c}}$, \\ Tatiana B. Medvedeva ${ }^{a}$, Ivan A. Lukoyanov ${ }^{a, b}$, \\ Vladimir A. Poluboyarov ${ }^{b, c}$, Oxana P. Taran*a,d,e, \\ Valentin N. Parmon ${ }^{\mathrm{a}}$ and Maria N. Timofeeva ${ }^{\mathrm{a}, \mathrm{b}}$ \\ ${ }^{a}$ Boreskov Institute of Catalysis SB RAS \\ 5 Lavrentiev, Novosibirsk, 630090, Russia \\ ${ }^{b}$ Novosibirsk State Technical University \\ 20 Karl Marx, Novosibirsk, 630073, Russia \\ 'Institute of Solid State Chemistry and Mechanochemistry SB RAS \\ 18 Kutateladze Str., Novosibirsk, 630090, Russia \\ 'Institute of Chemistry and Chemical Technology SB RAS \\ FRC "Krasnoyarsk Science Center SB RAS”" \\ 50/24 Akademgorodok, Krasnoyarsk, 660036, Russia \\ eSiberian Federal University \\ 79 Svobodny, Krasnoyarsk, 660041, Russia
} Received 04.02.2019, received in revised form 27.03.2019, accepted 11.05.2019

Catalytic systems based on tungsten carbide $\left(W_{n} C\right)$ containing mainly $W_{2} C$ were obtained by the method of self-propagating high-temperature synthesis from a mechanochemically activated mixture of tungsten oxide, metallic magnesium, carbon black and $\mathrm{CaCO}_{3}$. The phase composition of the formed materials was shown to depend on the amount of $\mathrm{CaCO}_{3}$. The catalytic properties of the materials were tested in the hydrolysis-hydrogenation of cellulose to ethylene glycol (EG) and 1,2-propylene glycol (PG). It was established that in the presence of $W_{n} C$ the main products of the reaction were $E G$ and $P G$ with a ratio of $P G / E G-1.5-1.8$. The deposition of nickel nanoparticles on the $W_{n} C$ surface increased the reaction rate and product yields. The maximum total yield of diols was $47.1 \mathrm{~mol} . \%$.

(c) Siberian Federal University. All rights reserved

* Corresponding author E-mail address: oxanap@bk.ru 
Keywords: self-propagating high-temperature synthesis, tungsten carbide, nickel, cellulose, hydrolysishydrogenation, ethylene glycol, 1,2-propylene glycol.

Citation: Gromov N.V., Zhdanok A.A., Medvedeva T.B., Lukoyanov I.A., Poluboyarov V.A., Taran O.P., Parmon V.N., Timofeeva M.N. Self-propagating high-temperature synthesis of materials based on tungsten carbide for one-pot hydrolysishydrogenolysis of cellulose into ethylene glycol and 1,2-propylene glycol, J. Sib. Fed. Univ. Chem., 2019, 12(2), $269-281$. DOI: $10.17516 / 1998-2836-0125$.

\title{
Самораспространяющийся высокотемпературный \\ синтез материалов на основе карбида вольфрама \\ для одностадийного процесса \\ гидролиза-гидрогенолиза целлюлозы \\ в этиленгликоль и 1,2-пропиленгликоль
}

\author{
Н.В. Громов ${ }^{\mathrm{a}, \boldsymbol{\sigma}}$, А.А. Жданок, \\ Т.Б. Медведева ${ }^{a}$, И.А. Лукоянов ${ }^{a, \sigma}$, В.А. Полубояров ${ }^{\tilde{\sigma}, \mathrm{s}}$, \\ О.П. Таран ${ }^{\text {a,r, }, \text { В.Н. Пармон }}{ }^{\text {a }}$, М.Н. Тимофеева ${ }^{a, \tilde{\sigma}}$ \\ ${ }^{a}$ Институт катализа им. Г.К. Борескова СО РАН \\ Россия, 630090, Новосибирск, пр. Академика Лаврентьева, 5 \\ ${ }^{6}$ Новосибирский государственный технический университет \\ Россия, 630073, Новосибирск, пр. Карла Маркса, 20 \\ ${ }^{6}$ Институт химии твердого тела и механохимии СО АН \\ Россия, 630090, Новосибирск, ул. Кутателадзе, 18 \\ 'Институт химии и химической технологии СО РАН \\ ФИЦ «Красноярский научный центр СО РАН» \\ Россия, 660036, Красноярск, Академгородок, 50/24 \\ ${ }^{\circ}$ Сибирский федеральный университет \\ Россия, 660041, Красноярск, пр. Свободныий, 79
}

\footnotetext{
Методом самораспространяющегося высокотемпературного синтеза из смеси оксида вольфрама, металлического магния, технического углерода и $\mathrm{CaCO}_{3}$ с использованием механохимическойобработки получены каталитические системы на основе карбида вольфрама $\left(W_{n} C\right)$, содержащие преимущественно $W_{2} C$. Показано, что фазовый состав образуюшихся материалов зависит от количества $\mathrm{CaCO}_{3}$. Каталитические свойства полученных материалов исследованы в реакции гидролиза-гидрогенолиза целлюлозы до низиих полиолов (этиленгликоль (ЭГ) и 1,2-пропиленгликоль (ПГ)). Установлено, что в присутствии $W_{n}$ С основными продуктами реакции являются ЭГ и ПГ с соотношением ПГ/ЭГ - 1,5-1,8. Нанесение наночастии никеля на поверхность $W_{n} C$ материалов повымает скорость реакиии и выход целевых продуктов. Максимальный суммарный выход диолов составил 47,1 мол. \%.
} 
Ключевые слова: самораспространяющийся высокотемпературныйсинтез, карбид вольфрама, никель, иеллюлоза, гидролиз-гидрогенолиз, этиленгликоль, 1,2-пропиленгликоль.

\section{Введение}

Этиленгликоль (ЭГ) и 1,2-пропиленгликоль (1,2-ПГ) - важные химические соединения, широко используемые в синтезе сложных полиэфиров. В настоящее время потребление гликолей составляет примерно 30 млн т в год и увеличивается со скоростью 5 \% в год [1]. В основном ЭГ и 1,2-ПГ получают из пропилена и этилена [2], однако из-за уменьшения запасов такого сырья все больше внимания привлекает синтез гликолей из возобновляемой растительной биомассы.

Наиболее перспективным сырьем для получения низших гликолей является целлюлоза основной компонент лигноцеллюлозной растительной биомассы. Экономически и экологически привлекательным методом превращения целлюлозы в низшие полиолы представляется одностадийный процесс гидролиза-гидрогенолиза в присутствии бифункциональных катализаторов (рис. 1). В ходе этого процесса целлюлоза гидролизуется с образованием глюкозы, а глюкоза частично изомеризуется во фруктозу, моносахариды после ретроальдольного расщепления на С2-C4 углеводы ([4+2], [3+3] и т.д.) и их последующего гидрирования образуют ЭГ и $1,2-П Г$.

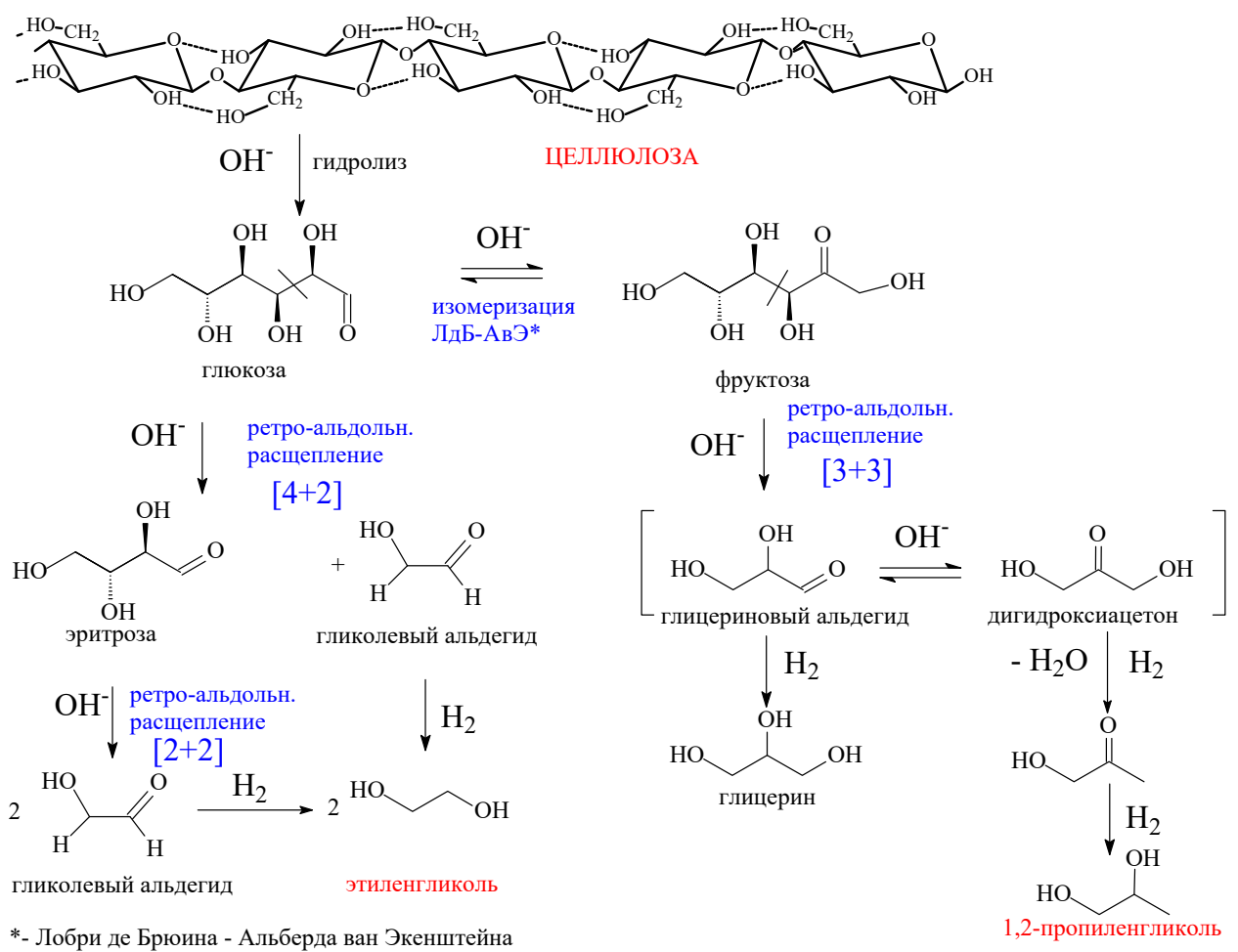

Рис. 1. Реакция гидролиза-гидрогенолиза целлюлозы с образованием гликолей

Fig. 1. The pathway of hydrolysis-hydrogenolysis of cellulose to glycols 
В литературе уже имеются примеры получения низших полиолов (ЭГ и 1,2-ПГ) из целлюлозы в присутствии различных W-содержащих каталитических систем [3-7]. Наибольший выход ЭГ был получен в случае применения каталитических систем на основе карбида вольфрама [8-11]. Так, применение карбида вольфрама, нанесенного на активированный уголь $\left(30 \% \mathrm{~W}_{2} \mathrm{C} /\right.$ AC) позволяет получать ЭГ с выходом 27,4 \% [8] (табл. 1). Введение в эту каталитическую систему наночастиц никеля позволило повысить выход ЭГ до 44-73 \%. Изменяя дисперсность наночастиц никеля и химическое состояние вольфрамовых центров, можно варьировать селективность процесса по ЭГ и 1,2-ПГ. Максимальный выход ЭГ (73 \%) с небольшим выходом $1,2-П Г ~(8,5 \%)$ был получен в присутствии $10 \% \mathrm{Ni}-30 \% \mathrm{~W}_{2} \mathrm{C} / \mathrm{AC}$.

Использование растительного сырья, богатого фруктозой, дает возможность получать 1,2ПГ в качестве основного продукта. Так, в работе [12] было показано, что при использовании в качестве субстрата клетчатки, выделенной из корня топинамбура и содержащей инулин, процесс гидролиза-гидрогенолиза в присутствии $\mathrm{W}_{2} \mathrm{C} / \mathrm{AC}$ и $\mathrm{Ni}-\mathrm{W}_{2} \mathrm{C} / \mathrm{AC}$ дает в основном 1,2-ПГ (табл. 1). Причина смены основного продукта в том, что инулин является полимером фруктозы, из которой и образуется 1,2-ПГ (рис. 1).

Отметим, что в одностадийном процессе гидролиза-гидрогенолиза целлюлозы, используя катализатор, состоящий из смеси 50\%-ного $\mathrm{WO}_{3} / \mathrm{Al}_{2} \mathrm{O}_{3}$ и $\mathrm{AУ,} \mathrm{также} \mathrm{можно} \mathrm{получать} 1,2-$-ПГ с

Таблица 1. Сравнение каталитических свойств изученных в данной работе каталитических систем с системами, описанными в литературе

Table 1. Comparison of the catalytic properties of the catalytic systems investigated at the present work and ones shown in the literature

\begin{tabular}{|c|c|c|c|c|c|c|}
\hline № & Катализатор & Условия реакции ${ }^{\sigma}$ & $\begin{array}{c}\text { Выход ЭГ } \\
(\%)\end{array}$ & $\begin{array}{c}\text { Выход 1,2- } \\
П Г ~(\%)\end{array}$ & $\begin{array}{c}(1,2-\Pi \Gamma+\Gamma Л) / \\
Э Г\end{array}$ & Ссылка \\
\hline 1 & CW-2 & $245^{\circ} \mathrm{C}, 50$ атм $\mathrm{H}_{2}, 300$ мин & 11,5 & 18,0 & 1,61 & $\begin{array}{l}\text { Данная } \\
\text { работа }\end{array}$ \\
\hline 2 & $1 \% \mathrm{Ni} / \mathrm{CW}-2$ & $245^{\circ} \mathrm{C}, 50$ атм $\mathrm{H}_{2}, 300$ мин & 16,8 & $28,3 / 2,0^{\mathrm{a}}$ & $1,80^{\mathrm{a}}$ & $\begin{array}{c}\text { Данная } \\
\text { работа }\end{array}$ \\
\hline 3 & $\mathrm{~W}_{2} \mathrm{C} / \mathrm{AC}$ & $245^{\circ} \mathrm{C}, 60$ атм $\mathrm{H}_{2}, 30$ мин & 27,9 & 5,6 & 0,20 & [9] \\
\hline 4 & $\mathrm{Ni}-\mathrm{W}_{2} \mathrm{C} / \mathrm{AC}$ & $245^{\circ} \mathrm{C}, 60$ атм $\mathrm{H}_{2}, 30$ мин & 61,0 & 7,6 & 0,12 & [9] \\
\hline 5 & $\mathrm{~W}_{2} \mathrm{C} / \mathrm{AC}$ & $245^{\circ} \mathrm{C}, 60$ атм $\mathrm{H}_{2}, 80$ мин $^{\text {в }}$ & 1,6 & $3,1 / 1,6^{\mathrm{a}}$ & 2,94 & {$[12]$} \\
\hline 6 & $1 \% \mathrm{Ni}-20 \% \mathrm{~W}_{2} \mathrm{C} / \mathrm{AC}$ & $245^{\circ} \mathrm{C}, 60$ атм $\mathrm{H}_{2}, 80$ мин $^{\text {в }}$ & 11,5 & $33,2 / 5,8^{a}$ & 3,39 & {$[12]$} \\
\hline 7 & $2 \% \mathrm{Ni}-20 \% \mathrm{~W}_{2} \mathrm{C} / \mathrm{AC}$ & $245^{\circ} \mathrm{C}, 60$ атм $\mathrm{H}_{2}, 80$ мин $^{\text {в }}$ & 11,2 & $33,5 / 8,8$ & 3,78 & {$[12]$} \\
\hline 8 & $4 \% \mathrm{Ni}-20 \% \mathrm{~W}_{2} \mathrm{C} / \mathrm{AC}$ & $245^{\circ} \mathrm{C}, 60$ атм $\mathrm{H}_{2}, 80$ мин $^{\text {в }}$ & 14,1 & $38,5 / 9,3$ & 3,39 & {$[12]$} \\
\hline 9 & $2 \% \mathrm{Ni}-30 \% \mathrm{~W}_{2} \mathrm{C} / \mathrm{AC}$ & $245^{\circ} \mathrm{C}, 60$ атм $\mathrm{H}_{2}, 80$ мин $^{\text {в }}$ & 8,3 & $26,4 / 4,2$ & 3,69 & {$[12]$} \\
\hline 10 & $\mathrm{Ni}-\mathrm{W} / \mathrm{TiO}_{2}$ & $245^{\circ} \mathrm{C}, 60$ атм $\mathrm{H}_{2}, 30$ мин & 36,8 & 1,5 & 0,04 & {$[17]$} \\
\hline 11 & Ni-W/SBA-15 & $245^{\circ} \mathrm{C}, 60$ атм $\mathrm{H}_{2}, 30$ мин & 36,8 & 2,0 & 0,05 & [17] \\
\hline 12 & Raney Ni-H ${ }_{2} \mathrm{WO}_{4}$ & $245^{\circ} \mathrm{C}, 60$ атм $\mathrm{H}_{2}, 30$ мин & 65,4 & 3,3 & 0,05 & {$[18]$} \\
\hline 13 & $\mathrm{Ni} / \mathrm{ZnO}_{2}$ & $245^{\circ} \mathrm{C}, 60$ атм $\mathrm{H}_{2}, 120$ мин & 19,1 & 34,4 & 1,80 & {$[19]$} \\
\hline 14 & $20 \mathrm{Ni}-26 \mathrm{ZnO} / \mathrm{CNT}^{\mathrm{B}}$ & $245^{\circ} \mathrm{C}, 60$ атм $\mathrm{H}_{2}, 90$ мин & 32,8 & $15,2 / 14,4^{\mathrm{a}}$ & $0,90^{\mathrm{a}}$ & {$[20]$} \\
\hline 15 & $20 \mathrm{Ni}-46 \mathrm{ZnO} / \mathrm{CNT}^{\mathrm{s}}$ & $245^{\circ} \mathrm{C}, 60$ атм $\mathrm{H}_{2}, 90$ мин & 31,3 & $14,0 / 12,4^{\mathrm{a}}$ & $0,84^{\mathrm{a}}$ & {$[20]$} \\
\hline
\end{tabular}

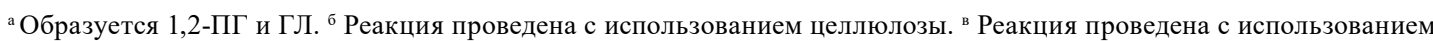

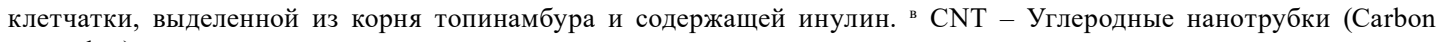
nanotubes) 
селективностью 40,9 \% при конверсии целлюлозы 21,2 \% [7]. К сожалению, вопрос регулирования селективности обсуждаемого одностадийного процесса по этим двум важным гликолям до сих пор мало рассматривался в литературе.

В данной работе изучены каталитические свойства систем на основе карбида вольфрама $\mathrm{W}_{2} \mathrm{C}$ в одностадийном процессе гидролиз-гидрогенолиза активированной микрокристаллической целлюлозы в низшие полиолы (ЭГ и ПГ). Акцент в работе сделан на выяснение основных причин, влияющих на скорость и селективность процесса. Традиционно карбид вольфрама получают при температурах выше 1500 으, что приводит к высоким затратам энергии, многооперационности и трудоемкости его получения. Традиционные методы дают грубодисперсный карбид вольфрама, малопригодный для использования в качестве катализаторов. Высокодисперсный $\mathrm{W}_{2} \mathrm{C}$ может быть получен механохимическим методом из смеси углерода и оксида вольфрама в присутствии $\mathrm{Mg}, \mathrm{Al}, \mathrm{Zn}$ в качестве восстановителей [13]. Недостатком данного метода является необходимость длительной механохимической активации (30-60 мин) при ускорении в искусственном поле тяжести $60 \mathrm{~g}$. Согласно данным работы [14], карбид вольфрама $\left(\mathrm{W}_{2} \mathrm{C}\right)$ образуется в процессе самораспространяющегося высокотемпературного синтеза (CBC) карбида вольфрама (WC) в качестве побочного продукта. В данной работе для получения карбида вольфрама $\left(\mathrm{W}_{2} \mathrm{C}\right)$ нами был использован комбинированный метод, основанный на сочетании механохимической активации и СВС. Применение комбинированного метода позволяет снизить время механохимической активации реакционной смеси и затраты энергии.

\section{Экспериментальная часть}

\section{Реактивы и материаль}

В работе без предварительной очистки в качестве стандартов для ВЭЖХ использовались следующие химические реактивы: D-фруктоза (Sigma-Aldrich), D-манноза (Sigma-Aldrich), D-глюкоза (Реахим, Москва), глицерин (99,9 \%, Acros), этиленгликоль (99,0 \%, Acros), пропиленгликоль (99,5 \%, Acros), изосорбид (99,9 \%, Acros). В качестве субстрата взята микрокристаллическая целлюлоза (фракция < 0,10 мм, ЗАО Вектон, Санкт-Петербург). Аргон (99,998 \%, ГОСТ 10157-70, ОАО Сибтехгаз, Новосибирск, Россия) применен в качестве инертного газа в реакторе, а водород (ГОСТ Р 51673-2000) - в качестве восстановителя. Вода, очищенная на установке Milli-Q (Millipore, Франция), использовалась для приготовления всех катализаторов и растворов.

\section{Приготовление катализаторов}

Для синтеза катализаторов использовали магний (ЗАО «Вектон») и технический углерод № 234 (ЗАО Карбон). $\mathrm{WO}_{3}$ был получен прокаливанием паравольфрамата аммония при $700{ }^{\circ} \mathrm{C}$ в течение 5 ч.

Синтез материалов на основе карбида вольфрама состоял из следующих стадий: (а) приготовление экзотермической смеси смешением $\mathrm{WO}_{3}, \mathrm{Mg}$, технического углерода, $\mathrm{CaCO}_{3}$ в необходимых количествах; (б) активация приготовленной экзотермической смеси в планетарной мельнице-активаторе АГО-2 в течение 1 мин (масса загружаемого материала $\approx 20$ г, стальные шары диаметром 5 мм, масса шаров 200 г, ускорение в искусственном поле тяжести 60 g); (в) термообработка смеси в режиме горения. Условия синтеза и характеристики об- 
Таблица 2. Условия синтеза и фазовый состав материалов на основе карбида вольфрама

Table 2. Conditions of synthesis and phase composition of the materials based on tungsten carbide

\begin{tabular}{|c|c|c|c|c|c|c|}
\hline \multirow{2}{*}{ Образец } & \multicolumn{4}{|c|}{ Условия синтеза } & \multicolumn{2}{c|}{ Фазовый состав продукта } \\
\cline { 2 - 7 } & $\begin{array}{c}\mathrm{Mg} / \mathrm{WO}_{3} \\
\text { моль/моль) }\end{array}$ & $\begin{array}{c}\mathrm{W} / \mathrm{C} \\
\text { (моль/моль) }\end{array}$ & $\begin{array}{c}\mathrm{CaCO}_{3} \\
(\text { масс. \%) }\end{array}$ & $\begin{array}{c}\mathrm{W} \\
(\text { масс. } \%)\end{array}$ & $\mathrm{W} / \mathrm{W}_{2} \mathrm{C}$ & $\mathrm{W}_{2} \mathrm{C} / \mathrm{WC}$ \\
\hline $\mathrm{CW}-1$ & $3 / 1$ & $1 / 2$ & 10 & 0 & 0,8 & 30 \\
\hline $\mathrm{CW}-2$ & $3 / 1$ & $1 / 2$ & 0 & 50 & 5 & 30 \\
\hline $\mathrm{CW}-3$ & $3 / 1$ & $1 / 4$ & 10 & 0 & 1,4 & 14 \\
\hline $\mathrm{CW}-4$ & $3 / 1$ & $1 / 4$ & 5 & 0 & 1,3 & 7,4 \\
\hline
\end{tabular}

разцов приведены в табл. 2. Очистка полученного продукта горения от побочных продуктов (оксидов магния и кальция) включала в себя (а) обработку 10\%-ным раствором щавелевой кислоты до их полного удаления; (б) промывку водой до нейтральной реакции промывных вод; (в) сушку целевого продукта до воздушно-сухого состояния при комнатной температуре и при $100{ }^{\circ} \mathrm{C}$ в течение 3 ч.

$\mathrm{Ni-coдержащие} \mathrm{катализаторы} \mathrm{Ni/CW-2} \mathrm{с} \mathrm{содержанием} \mathrm{никеля} 1$ и 3 мас. \% были приготовлены нанесением $\mathrm{Ni}\left(\mathrm{NO}_{3}\right)_{2}$ из водного раствора методом пропитки по влагоемкости с последующей сушкой на воздухе и восстановлением в токе водорода при $400{ }^{\circ} \mathrm{C}$ в течение 3 ч.

\section{Физико-химические методы исследования цееллюлозы и катализаторов}

Активацию целлюлозы проводили в планетарной мельнице дискретного действия «Pulverizette 5» («Fristch», Idar-Oberstein, Германия [15]) в течение 40 мин. Объем барабана 0,25 дм³ $^{3}$ масса загружаемой целлюлозы 15 г, диаметр шаров 20 мм, количество шаров 7 шт., потребляемая мощность 1,5 кВт, ускорение в искусственном поле тяжести $22 \mathrm{~g}$.

Дифрактограммы целлюлозы и были получены на порошковом дифрактометре X’TRA (Thermo, Швейцария, вертикальный гониометр $\theta / 2 \theta$-геометрии, фокусировки по методу Брэгга-Брентано, точечный полупроводниковый детектор). Источником излучения является рентгеновская трубка с медном анодом, средняя длина волны излучения $\mathrm{CuK} \alpha=0,15418$ нм. Ток генератора 35 мА, напряжение 35 кВ (мощность 1,225 кВт).

Измерение размера частиц целлюлозы проводили с помощью оптического микроскопа «Биомед-5» (ООО Биомед-М, г. Москва, Россия), оснащенного цифровой фотокамерой. Средний диаметр частиц целлюлозы определяли для каждого образца вычислением среднего значения из диаметров около 100 частиц, наблюдаемых на микрофотографиях.

Поверхностную кислотность образцов ( $\mathrm{pH}_{\mathrm{TH}}$, точка нулевого заряда) определяли методом массового титрования (методом Зеренсена-де Брюина) [16]. Измерение осуществляли на комбинированном pH-метре/кондуктометре Mettler Tolledo Multi S47. Основные результаты приведены в табл. 3.

\section{Каталитические эксперименты}

Одностадийный процесс гидролиза-гидрогенолиза целлюлозы проводили в автоклаве из нержавеющей стали объемом 150 мл (ИК СО РАН) при $245{ }^{\circ} \mathrm{C}$ и давлении водорода 50 атм

$$
-274-
$$


Таблица 3. Одностадийный процесс гидролиза-гидрогенолиза целлюлозы в присутствии систем на основе карбида вольфрама ${ }^{a}$

Table 3. One-pot hydrolysis-hydrogenolysis of cellulose in the presence of the catalytic systems based on tungsten carbide

\begin{tabular}{|c|c|c|c|c|c|c|c|}
\hline & \multirow{2}{*}{$\mathrm{pH}_{\mathrm{TH} 3}{ }^{\sigma}$} & \multirow{2}{*}{$\begin{array}{l}\text { Время } \\
\text { (мин) }\end{array}$} & \multicolumn{3}{|c|}{ Выход ( \%) } & \multirow{2}{*}{$\begin{array}{c}(1,2-П Г+Г Л) / Э Г ~ \\
\text { (моль/моль) }\end{array}$} & \multirow{2}{*}{$\begin{array}{c}\Sigma \text { Выход } \\
(\%)\end{array}$} \\
\hline & & & ЭГ & 1,2-ПГ & ГЛ & & \\
\hline \multirow[t]{3}{*}{ CW-1 } & 5,36 & 60 & 5,1 & 4,3 & 1,7 & 1,18 & 11,1 \\
\hline & & 300 & 9,2 & 15,1 & 0,0 & 1,64 & 24,3 \\
\hline & & 360 & 10,1 & 16,4 & 0,0 & 1,62 & 26,5 \\
\hline \multirow[t]{3}{*}{$\mathrm{CW}-2$} & 4,97 & 60 & 5,0 & 4,9 & 1,1 & 1,20 & 11,0 \\
\hline & & 300 & 11,5 & 17,7 & 0,0 & 1,54 & 29,2 \\
\hline & & 360 & 11,5 & 18,5 & 0,0 & 1,61 & 30,0 \\
\hline \multirow[t]{3}{*}{$\begin{array}{l}1 \% \mathrm{Ni} / \\
\mathrm{CW}-2\end{array}$} & 9,32 & 60 & 7,5 & 12,6 & 0,5 & 1,75 & 20,6 \\
\hline & & 300 & 16,8 & 28,3 & 2,0 & 1,80 & 47,1 \\
\hline & & 360 & 16,3 & 27,4 & 1,5 & 1,77 & 45,2 \\
\hline \multirow[t]{3}{*}{$\begin{array}{c}3 \% \mathrm{Ni} / \\
\mathrm{CW}-2\end{array}$} & 9,67 & 60 & 7,8 & 13,7 & 1,1 & 1,90 & 22,6 \\
\hline & & 300 & 16,2 & 26,0 & 2,0 & 1,73 & 44,2 \\
\hline & & 360 & 14,5 & 22,8 & 1,7 & 1,69 & 39,0 \\
\hline \multirow[t]{3}{*}{ CW-3 } & 4,12 & 60 & 7,1 & 4,3 & 1,2 & 0,77 & 12,6 \\
\hline & & 300 & 9,6 & 15,1 & 0,0 & 1,57 & 24,7 \\
\hline & & 360 & 9,7 & 15,4 & 0,0 & 1,59 & 25,1 \\
\hline \multirow[t]{3}{*}{ CW-4 } & 4,42 & 60 & 6,4 & 6,1 & 0,9 & 1,09 & 13,4 \\
\hline & & 300 & 9,0 & 15,4 & 0,0 & 1,71 & 24,4 \\
\hline & & 360 & 9,5 & 15,1 & 0,0 & 1,59 & 24,6 \\
\hline
\end{tabular}

а Условия эксперимента: 0,5 г целлюлозы, 0,5 г катализатора, 0,04 г Са(ОН $)_{2}$ в 50 мл воды, давление водорода 50 атм, $245{ }^{\circ} \mathrm{C} .{ }^{6} \mathrm{pH}_{\mathrm{TH} 3}-$ точка нулевого заряда образца на основе карбида вольфрама.

(суммарное давление в субкритических условиях 100 атм) при интенсивном перемешивании магнитной мешалкой (1000 об/мин). В реактор загружали 50 мл воды, 0,5 г активированной целлюлозы, 0,5 г катализатора и 0,04 г $\mathrm{Ca}(\mathrm{OH})_{2}$. Реактор закрывали, удаляли кислород 6-кратным промыванием системы аргоном, затем напускали водород до 50 атм и начинали нагрев реакционной смеси. Момент достижения необходимой температуры служил началом отсчета времени эксперимента. В ходе реакции через определенные интервалы времени отбирали пробы реакционной смеси для анализа методами ВЭЖХ и анализа общего органического углерода (OOY).

ВЭЖХ-анализ проводили на хроматографе Shimadzu Prominence LC-20, оборудованном рефрактометрическим и диодноматричным детекторами. Анализ на сахара и многоатомные спирты проводили на колонке Rezex ROA-Organic Acids (Phenomenex, 300 мм·5,0 мм), термостатированной при $40{ }^{\circ} \mathrm{C}$. В качестве элюента использовали подаваемый со скоростью 0,6 мл/мин 1,25 мМ водный раствор серной кислоты. Определение ООУ проводили на анализаторе углерода multi N/C $2100 \mathrm{~s}$ (Analytik Jena). 
Выходы продуктов одностадийного процесса гидролиза-гидрогенолиза целлюлозы расчитывали в мольных процентах ( \%) по формуле

$$
Y_{\text {прод }}=\frac{C_{\text {прод }} V}{N_{c}\left(\frac{m_{\text {чели }}}{M_{\text {гль }}}\right)} \cdot 100 \%,
$$

где $\mathrm{Y}_{\text {прод }}$ - выход продукта; $\mathrm{C}_{\text {прод }}$ - концентрация продукта (моль $\pi^{-1}$ ); $\mathrm{V}$ - объем реакционной смеси (л); $\mathrm{N}_{\mathrm{C}}$ - коэффициент, учитывающий мольное соотношение углерода между продуктом и остатком глюкозы в целлюлозе; $\mathrm{m}_{\text {целл }}$ масса целлюлозы (г); $\mathrm{M}_{\text {глю }}$ - молярная масса остатка глюкозы в целлюлозе $\left(162\right.$ г'моль $\left.{ }^{-1}\right)$.

\section{Результаты и их обсуждение}

Синтез материалов на основе карбида вольфрама

Материалы на основе карбида вольфрама $\left(\mathrm{W}_{\mathrm{n}} \mathrm{C}\right)$, содержащие преимущественно $\mathrm{W}_{2} \mathrm{C}$, были получены методом $\mathrm{CBC}$ из смеси $\mathrm{W}, \mathrm{WO}_{3}, \mathrm{Mg}$, технического углерода и $\mathrm{CaCO}_{3}$ с использованием предварительной механохимической обработки в течение 1 мин. Условия синтеза материалов (образцы CW-n) приведены в табл. 2. CBC происходит во всех перечисленных в таблице смесях. Отметим, что при использовании смеси $\mathrm{WO}_{3}, \mathrm{Mg}$ и технического углерода контролировать реакцию и выход целевого карбида $\mathrm{W}_{2} \mathrm{C}$ крайне сложно из-за высокой скорости реакции и образования $\mathrm{W}$ в качестве основного продукта с небольшим содержанием $\mathrm{W}_{2} \mathrm{C}$ ( $<5 \%)$. Введение в смесь вольфрама или карбоната кальция позволяет снизить скорость горения и повысить выход карбида вольфрама $\mathrm{W}_{2} \mathrm{C}$.

Фазовый состав получаемых продуктов был исследован методом рентгенофазового анализа. На рентгенограммах (рис. 2) всех полученных образцов отсутствуют рефлексы, характерные для $\mathrm{WO}_{3}\left(2 \Theta=23,49,24,23,29,37\right.$ и $\left.35,29^{\circ}\right)$, и присутствуют рефлексы, относящиеся к металлическому вольфраму $\left(2 \Theta=40,26\right.$ и $\left.58,27^{\circ}\right)$. Это указывает на полное протекание реакции восстановления оксида вольфрама металлическим магнием:

$$
\mathrm{WO}_{3}+3 \mathrm{Mg} \rightarrow \mathrm{W}+3 \mathrm{MgO} .
$$

Кроме того, в рентгенограммах наблюдаются рефлексы карбидов вольфрама WC $(2 \Theta=31,58$ и $\left.48,42^{\circ}\right)$ и $\mathrm{W}_{2} \mathrm{C}\left(2 \Theta=34,52,38,03\right.$ и $\left.39,57^{\circ}\right)$. Наличие небольших количеств $\mathrm{WC}$ объясняется протекающими в системе последовательными реакциями:

$$
2 \mathrm{~W}+\mathrm{C} \rightarrow \mathrm{W}_{2} \mathrm{C} \rightarrow \mathrm{W}_{2} \mathrm{C}+\mathrm{C} \rightarrow 2 \mathrm{WC} .
$$

Фазовый состав материалов зависит от количества введенных добавок. Введение в исходную смесь как металлического вольфрама, так и $\mathrm{CaCO}_{3}$ позволяет получать $\mathrm{W}_{2} \mathrm{C}$. Отношение интенсивностей рефлексов $\mathrm{I}_{39,57} / \mathrm{I}_{48,42}\left(\mathrm{~W}_{2} \mathrm{C} / \mathrm{WC}\right)$ в обоих случаях (табл. 2, образцы CW-1 и CW-2) равно 30. Однако величина отношения $\mathrm{I}_{40,26} / \mathrm{I}_{39,57}$ в образце $\mathrm{CW}-2$ выше, чем в образце $\mathrm{CW}-1$, что указывает на неполное превращение вольфрама в $\mathrm{W}_{2} \mathrm{C}$.

Исследование влияния содержания $\mathrm{CaCO}_{3}$ в исходной реакционной смеси $\left(\mathrm{WO}_{3}, \mathrm{Mg}\right.$ и технический углерод) на фазовый состав продукта показало слабую зависимость отношения $\mathrm{W} / \mathrm{W}_{2} \mathrm{C}\left(\mathrm{I}_{40,26} / \mathrm{I}_{39,57}\right)$ (табл. 2, образцы $\mathrm{CW}-3$ и $\left.\mathrm{CW}-4\right)$ от этого фактора. Наибольшее влияние 

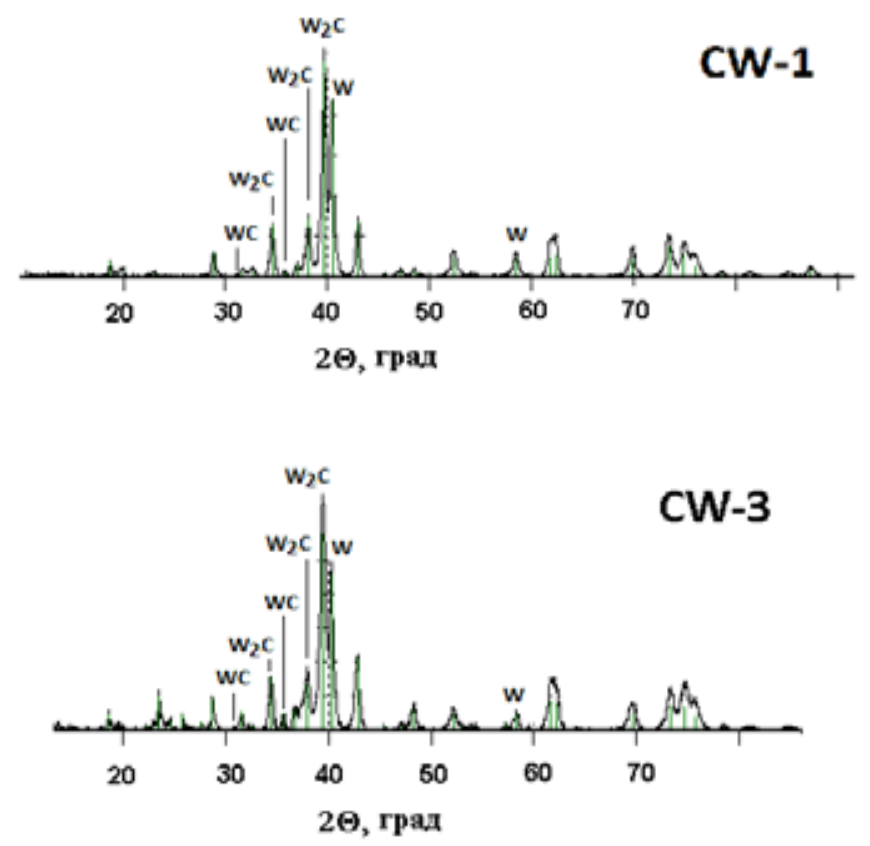

Рис. 2. Рентгенограммы образцов CW-1 и CW-3

Fig. 2. X-ray patterns of CW-1 and CW-3 samples

$\mathrm{CaCO}_{3}$ оказывал на отношение $\mathrm{W}_{2} \mathrm{C} / \mathrm{WC}$. В образце $\mathrm{CW}-3$, содержащем 10 мас. \% $\mathrm{CaCO}_{3}$, отношение $\mathrm{W}_{2} \mathrm{C} / \mathrm{WC}$ выше $\left(\mathrm{I}_{39,57} / \mathrm{I}_{48,42}=14\right)$ почти в 2 раза, чем в образце $\mathrm{CW}-4$, содержащем 5 мас. \% $\mathrm{CaCO}_{3}\left(\mathrm{I}_{39,57} / \mathrm{I}_{48,42}=7,4\right)$.

\section{Каталитические свойства материалов на основе карбида вольфрама}

Каталитические свойства полученных систем на основе карбида вольфрама были исследованы в реакции гидролиза-гидрогенолиза целлюлозы в низшие полиолы. Реакцию проводили при температуре $245^{\circ} \mathrm{C}$, давлении водорода 50 атм, концентрациях микрокристаллической целлюлозы и катализатора 10 г/л и $\mathrm{Ca}(\mathrm{OH})_{2} 0,8$ г/л. Основными продуктами реакции были ЭГ и 1,2-ПГ (табл. 3). Кроме того, в жидкой фазе был обнаружен в небольшом количестве глицерин (ГЛ). Отметим, что указанные продукты не наблюдались без введения в реакционную систему $\mathrm{Ca}(\mathrm{OH})_{2}$, а основными продуктами были глюкоза, сорбитол и маннитол. Это свидетельствует о важной роли реакции ретроальдольного расщепления, катализируемой основаниями, в данном случае $\mathrm{Ca}(\mathrm{OH})_{2}$, в суммарном процессе гидрогенолиза сахаров.

Типичные кинетические кривые накопления продуктов в ходе реакции в присутствии $\mathrm{CW}-2$ показаны на рис. $3 a$. Выход основных продуктов реакции ЭГ и 1,2-ПГ непрерывно возрастал во времени, а выход ГЛ через 60 мин после начала реакции снижался. На рис. 36 показана зависимость выхода ГЛ через 60 мин реакции от соотношения $\mathrm{W}_{2} \mathrm{C} / \mathrm{WC}$ в катализаторе. Хорошо прослеживается тенденция роста выхода ГЛ с увеличением этого соотношения. Это может указывать на важную роль $\mathrm{W}_{2} \mathrm{C}$ в процессе гидрирования 1,3-дигидроксиацетона и глицеральдегида (рис. 1). Интересно, что скорость исчезновения ГЛ в растворе снижается с увеличением количества $\mathrm{W}_{2} \mathrm{C}$ в катализаторе. Вероятно, кристаллическая структура $\mathrm{W}_{2} \mathrm{C}$ в большей степени 


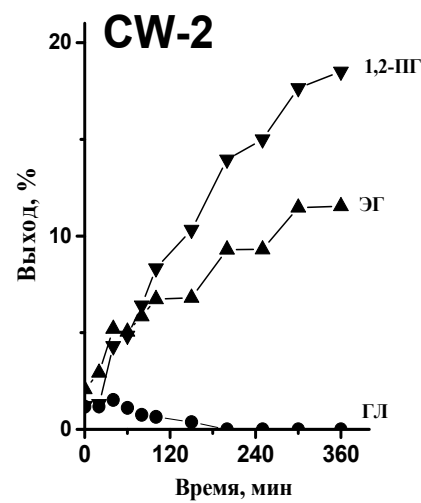

6

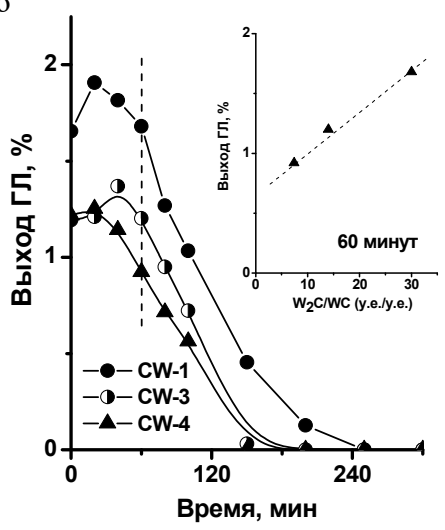

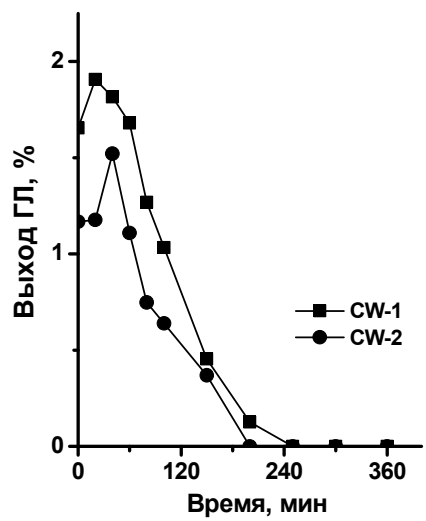

Рис. 3. Кинетика накопления ЭГ, 1,2-ПГ и ГЛ в ходе реакции в присутствии систем на основе карбида вольфрама

Fig. 3. Kinetic curves of EG, 1,2-PG and GL formation in the presence of the catalysts based on tungsten carbide

благоприятна для адсорбции 1,3-дигидроксиацетона и, соответственно, для его последующей дегидратации и гидрирования, чем для адсорбции и гидрирования глицеральдегида.

Кроме того, выход ГЛ определяется и содержанием W в катализаторе. На рис. $3 в$ показана кинетика расходования ГЛ в ходе реакции в присутствии CW-1 и CW-2 образцов с примерно одинаковым отношением $\mathrm{W}_{2} \mathrm{C} / \mathrm{WC}$. Видно, что ГЛ расходуется быстрее в присутствии $\mathrm{CW}-2$, в котором $\mathrm{W}$ содержится больше $\left(\mathrm{W} / \mathrm{W}_{2} \mathrm{C}=5\right)$, чем в присутствии $\mathrm{CW}-1\left(\mathrm{~W} / \mathrm{W}_{2} \mathrm{C}=0,8\right)$. Стоит отметить и тот факт, что в присутствии CW-2 суммарный выход всех продуктов (ЭГ, 1,2-ПГ и ГЛ) выше, чем в присутствии CW-1 (табл. 3). Все это может указывать на влияние вольфрама на процессы гидрирования образующихся интермедиатов. Таким образом, среди изученных вольфрамсодержащих систем максимальный выход низших полиолов (ЭГ и 1,2-ПГ) наблюдается в присутствии CW-2 (30,0 \% за 360 мин).

Для проверки возможности повышения выхода низших полиолов на основе образца CW-2 были приготовлены катализаторы, содержащие наночастицы никеля с содержанием 1 и 3 масс. \%. Основные результаты исследования каталитических свойств $1 \% \mathrm{Ni} / \mathrm{CW}-2$ и $3 \% \mathrm{Ni} /$ $\mathrm{CW}-2$ приведены в табл. 3. Как и в присутствии $\mathrm{CW}-2$, основными продуктами реакции оказались ЭГ, 1,2-ПГ и ГЛ. Как видно из полученных данных, введение наночастиц никеля в целом позволяет повысить выход продуктов примерно в 1,5 раза. Прежде всего, это можно объяснить изменением природы и/или концентрации кислотно-основных центров носителя в результате закрепления наночастиц никеля на поверхности $\mathrm{CW}-2$. Поверхностная кислотность катализаторов $\left(\mathrm{pH}_{\mathrm{TH}}\right)$, измеренная методом массового титрования, существенно уменьшилась для $1 \% \mathrm{Ni} / \mathrm{CW}-2(9,32)$ и $3 \% \mathrm{Ni} / \mathrm{CW}-2(9,67)$ по сравнению с носителем CW-2 $(4,97)$. Формирование осно́вных центров в $1 \% \mathrm{Ni} / \mathrm{CW}-2$ и $3 \% \mathrm{Ni} / \mathrm{CW}-2$, очевидно, повышает скорость процессов ретроальдольного расщепления (рис. 1).

Кинетические кривые накопления продуктов ходе реакции в присутствии $1 \% \mathrm{Ni} / \mathrm{CW}-2$ показаны на рис. 4. Корреляции между выходом продуктов и временем проведения реакции аналогичны корреляциям, наблюдаемым в присутствии CW-2 (рис. 3a). Однако скорость накопле- 


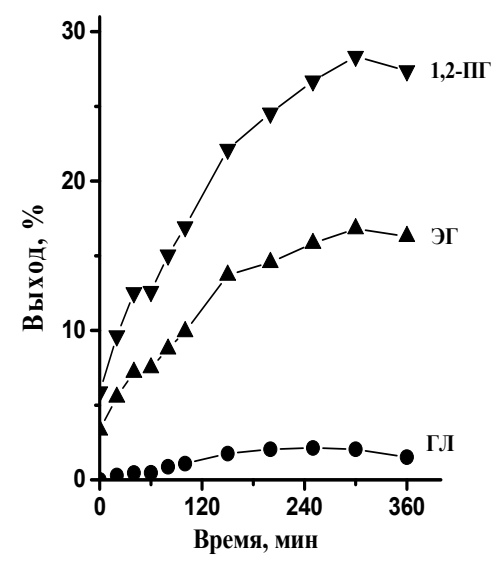

Рис 4. Кинетика накопления ЭГ, 1,2-ПГ и ГЛ в ходе реакции в присутствии катализатора 1 \% $\mathrm{Ni} / \mathrm{CW}-2$

Fig. 4. Kinetic curves of EG, 1,2-PG and GL formation in the presence of $1 \% \mathrm{Ni} / \mathrm{CW}-2$ catalyst

ния и расходования ГЛ существенно снижается, что, вероятно, связано с влиянием наночастиц никеля на процессы гидрирования интермедиатов.

Влияние наночастиц никеля в Ni/CW-2 катализаторах на процессы гидрирования также указывает и на характер изменения во времени соотношения (1,2-ПГ+ГЛ)/ЭГ (табл. 3). Величина отношения (1,2-ПГ+ГЛ)/ЭГ в присутствии CW-1, CW-2, CW-3 и CW-4 систем растет в ходе реакции, тогда как в присутствии $\mathrm{Ni} / \mathrm{CW}-2$ катализаторов это отношение практически не меняется. Рост величины (1,2-ПГ+ГЛ)/ЭГ, вероятно, связан с «активацией» ионов вольфрама в ходе

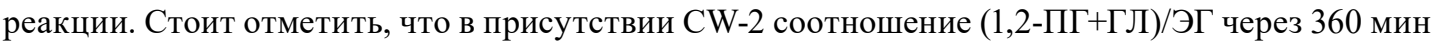
реакции $(1,61)$ очень близко к величине, наблюдаемой в присутствии $1 \% \mathrm{Ni} / \mathrm{CW}-2$ и $3 \% \mathrm{Ni} / \mathrm{CW}-2$ $(1,77$ и 1,69$)$.

Выход продуктов реакции также зависит от количества закрепленного никеля на поверхности CW-2 (табл. 3). Максимальный выход наблюдается для катализатора $1 \% \mathrm{Ni} / \mathrm{CW}-2$. В его присутствии через 300 мин суммарный выход низших полиолов составил 47,1\%, а соотно-

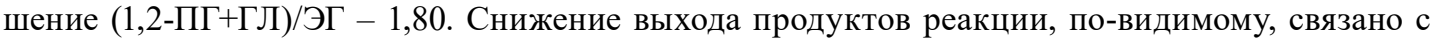
укрупнением металлических частиц при увеличении количества никеля в образце.

Интересно сравнить полученные результаты с данными для вольфрам- и никельсодержащих систем, представленных в литературе. Как видно из данных табл. 1, выход 1,2-ПГ и

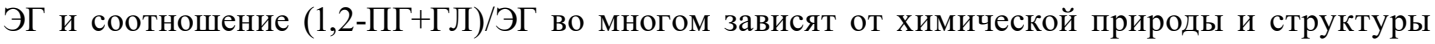
носителя. В присутствии $\mathrm{WC}-2$, в котором $\mathrm{W}_{2} \mathrm{C}$ находится на поверхности $\mathrm{W}$, основным продуктом является 1,2-ПГ (табл. 3, № 1). В присутствии каталитической системы $\mathrm{W}_{2} \mathrm{C} / \mathrm{AC}$ (табл. 3, № 3), в которой $\mathrm{W}_{2} \mathrm{C}$ находится на поверхности активированного угля, в основном образуется ЭГ. Исходя из структурных данных для каталитических систем, можно предположить, что адсорбция и изомеризация моносахарида на поверхности образца $\mathrm{CW}-2$ приводят к образованию фруктозы, которая в дальнейшем превращается в 1,2-ПГ (рис. 1). В то же время структура и наличие большого количества кислородсодержащих групп различной химической природы на поверхности активированного угля способствуют адсорбции и изомеризации моносахарида предпочтительно в форме глюкозы, которая в дальнейшем превращается в ЭГ (рис. 1). Сравне- 
ние каталитических характеристик $1 \% \mathrm{Ni} / \mathrm{WC}-2$ со свойствами различных никельсодержащих систем также указывает на роль носителя в адсорбции моносахарида и его последующих превращениях.

\section{Заключение}

Разработан новый метод самораспространяющегося высокотемпературного синтеза карбидов вольфрама карбидов вольфрама из смеси оксида вольфрама, металлического магния, технического углерода и $\mathrm{CaCO}_{3}$ с использованием предварительной механохимической обработки, позволяющий стабилизировать фазу карбида вольфрама $\mathrm{W}_{2} \mathrm{C}$, каталитически активную в реакции гидролиза-гидрогенолиза целлюлозы, в низшие диолы (этиленгликоль и 1,2-пропиленгликоль). Наибольшую активность в указанном процессе показал образец с фазовым соотношением $\mathrm{W} / \mathrm{W}_{2} \mathrm{C}=5$ и $\mathrm{W}_{2} \mathrm{C} / \mathrm{WC}=30$, в присутствии которого удалось получить этилен- и пропиленгликоли с выходами 11,5 и 18,5 мол. \% соответственно.

Приготовлены катализаторы, содержащие высокодисперсный никель, закрепленный на карбиде вольфрама в количестве 1 и 3 мас. \%. Показано, что нанесение никеля увеличивает активность катализатора и выходы целевых продуктов. $1 \% \mathrm{Ni} / \mathrm{CW}-2$, позволяет получать этилен- и пропиленгликоли с максимальными выходами до 16,3 и 28,3 мол. \% соответственно.

Важным достижением работы является получение пропиленгликоля в качестве основного продукта.

\section{Благодарности}

Работа выполнена при финансовой поддержке Российского фонда фундаментальных исследований (грант 17-03-01142).

\section{Список литературы}

1. Pang J., Zheng M., Sun R., Wang A., Wang X., Zhang T. Synthesis of ethylene glycol and terephthalic acid from biomass for producing PET. Green Chem. 2016. Vol. 18. P. 342-359.

2. Yue H., Zhao Y., Ma X., Gong J. Ethylene glycol: properties, synthesis, and applications. Chem. Soc. Rev. 2012. Vol. 41, P. 4218-4244.

3. Zheng M.Y., Wang A.Q., Ji N., Pang J.F., Wang X.D., Zhang T. Transition metal-tungsten bimetallic catalysts for the conversion of cellulose into ethylene glycol. ChemSusChem 2010. Vol. 3, P. 63-66.

4. Zhang Y., Wang A., Zhang T. A new 3D mesoporous carbon replicated from commercial silica as a catalyst support for direct conversion of cellulose into ethylene glycol. Chem. Commun. 2010. Vol. 46, P. 862-864.

5. Li N., Zheng Y., Wei L., Teng H., Zhou J. Metal nanoparticles supported on $\mathrm{WO}_{3}$ nanosheets for highly selective hydrogenolysis of cellulose to ethylene glycol. Green Chem. 2017. Vol. 19, P. 682-691.

6. Hamdy M.S., Eissa M.A., Keshk S.M.A.S. New catalyst with multiple active sites for selective hydrogenolysis of cellulose to ethylene glycol. Green Chem. 2017. Vol. 19, P. 5144-5151.

7. Liu Y., Luo C., Liu H. Tungsten trioxide promoted selective conversion of cellulose into propylene glycol and ethylene glycol on a ruthenium catalyst. Angew. Chem.Int. Ed. 2012. Vol. 51, P. 3249-3253. 
8. Ji N., Zheng M., Wang, A., Zhang T., Chen J.G. Nickel-promoted tungsten carbide catalysts for cellulose conversion: Effect of preparation methods. ChemSusChem 2012. Vol. 5, P. 939-944.

9. Ji N., Zhang T. Zheng M.Y., Wang A.Q., Wang H., Wang X.P., Chen J.G. Direct Catalytic Conversion of Cellulose into Ethylene Glycol Using Nickel-Promoted Tungsten Carbide Catalysts. Angew Chem Int Ed. 2008. Vol. 47, P. 8510-8513.

10. Ji N., Zhang T., Zheng M.Y., Wang A.Q., Wang H., Wang X.D., Shu Y.Y., Stottlemyer A.L. Catalytic conversion of cellulose into ethylene glycol over supported carbide catalysts. J. G. Chen. Catal. Today. 2009. Vol. 147, P. 77-85.

11. Ooms R., Dusselier M., Geboers J.A., de Beeck B.O., Verhaeven R., Gobechiya E., Martens J.A., Redl A., Sels B.F. Conversion of sugars to ethylene glycol with nickel tungsten carbide in a fed-batch reactor: high productivity and reaction network elucidation. Green Chem. 2014. Vol. 16, P. 695-707.

12. Zhou L., Wang A., Li C., Zheng M., Zhang T. Selective Production of 1,2-Propylene Glycol from Jerusalem Artichoke Tuber using Ni-W ${ }_{2}$ C/AC Catalysts. ChemSusChem. 2012. Vol. 5, P. 932938.

13. Патент 2388689 РФ. Молчанов В.В., Гойдин В.В. Способ получения карбида вольфрама $\mathrm{W}_{2}$ С. Опубл. 10.05.2010. [Patent 2388689 RU. Molchanov V.V., Goiding V.V., Synthesis of tungsten carbide $\mathrm{W}_{2}$ C. Publ. Data 10.05.2010 (In Russ.)]

14. Патент 2200128 РФ. Боровинская И.П., Вершинников В.И., Гозиян А.В., Игнатьева Т.И., Маржанов А.Г. Способ получения карбида вольфрама и карбид вольфрама, полученный этим способом. Опубл. 10.03.2003. [Patent 2200128 RU. Borovinskaya I.P., Vershinnikov V.I., Goziyan A.V., Ignatieva T.I., Marzhanov A.G. Synthesis of tungsten carbide and tungsten carbide synthesized this method. Publ. Data 10.03.2003 (In Russ.)]

15. Klaus W., Nolze G. Powder cell - a program for the representation and manipulation of crystal structures and calculation of the resulting X-ray powder patterns. J. Appl. Crystallogr. 1996. Vol. 29, P. 301-303.

16. Иконникова К.В. Теория и практика $\mathrm{pH-метрического} \mathrm{определения} \mathrm{кислотно-основных}$ свойств поверхности твердых тел: учебное пособие. Томск: Изд-во Томского политехнического университета, 2011. 85 c. [Ikonnikova K.V. Theory and practice of pH-metric determination of acidbase properties of the surface of solids: a tutorial. Tomsk: Publishing House of Tomsk Polytechnic University, 2011. 85 p. (In Russ.)]

17. Zheng M.-Y., Wang A.-Q., Ji N., Pang J.-F., Wang X.-D., Zhang T. Transition metal-tungsten bimetallic catalysts for the conversion of cellulose into ethylene glycol. ChemSusChem 2010. Vol. 3, P. 63-66.

18. Tai Z.J., Zhang J.Y., Wang A.Q., Pang J.F., Zheng M.Y., Zhang T. Catalytic Conversion of Cellulose to Ethylene Glycol over a Low-Cost Binary Catalyst of Raney Ni and Tungstic Acid. ChemSusChem 2013. Vol. 6, P. 652-658.

19. Wang X.C., Meng L.Q., Wu F., Jiang Y.J., Wang L., Mu X.D. Efficient conversion of microcrystalline cellulose to 1,2-alkanediols over supported Ni catalysts. Green Chem. 2012. Vol. 14, P. 758-765.

20. Liland I.S. One-pot conversion of cellulose to ethylene glycol and propylene glycol over nickel zinc oxide catalysts with CNT support. Master's thesis. Trondheim: Publishing House of Norwegian University of Science and Technology, 2013. $160 \mathrm{c}$.

$$
-281-
$$

